\title{
UN NOVELISTA POCO CONOCIDO: JOSÉ CAMERINO Y SUS NOVELAS AMOROSAS
}

MARIA DOLORES LóPEZ DIAZZ

Se ha repetido hasta la saciedad que de los dos géneros «estrella» de la literatura española del siglo XVII, el teatro y la novela, ha sido el teatro el que ha acaparado la atención de los estudiosos, mientras que han sido menos los que se han ocupado de la novela posterior a Cervantes. Tal es así que, todavía hoy, muchos novelistas continúan siendo prácticamente desconocidos. Ése es el caso de José Camerino del que, aunque muy someramente, quiero hoy ocuparme.

No son muchas las noticias biográficas que tenemos de José Camerino'. Sabemos que era italiano, de la ciudad de Fano, a orillas del Adriático... que vi-

I La mayor parte de las noticias biográficas que tenemos de José Camerino las debemos a un artículo de Ezıo LEVI, del año 1934, titulado «Un episodio sconociuto nella storia della novella spagnuola" - Boletín de la Real Academia Española XXI (1934), págs. 687-763- basado en el manuscrito 4.162 de la Biblioteca Nacional de Madrid: Origine dell'antica et nobile famiglia de Camerini nella cittá di Camerino. Con anterioridad, D. LuIS Fernández-GuerRA Y ORBE, en su estudio Don Juan Ruiz de Alarcón y Mendoza -(Madrid: Rivadeneira, 1871), páginas 403-405- le había dedicado unas líneas con motivo de la amistad de ambos escritores. Ya en nuestros días, HOMERo SERIS, en su obra Nuevo ensayo de una biblioteca española de libros raros y curiosos -2 vols. (Nueva York: 1969) 1: fascículo 2- hace un breve bosquejo de la biografía de Camerino basándose principalmente en el trabajo de LEVI, y más recientemente, Evangelina Rodriguez en Novela corta marginada del siglo XVII español. Formulación sociológica en José Camerino y Andrés de Prado - (Valencia: Universidad, 1979)-, hace una interesante aportación al tema, confrontando, aumentando y corrigiendo los datos suministrados por dichos autores. 
no a España en su juventud ${ }^{2}$ y que una vez aquí, se caś con una española, Dña. Agueda Vita y Matarrubia, y se instaló en Madrid, donde desempeñó una serie de cargos burocráticos al servicio del Vaticano, y donde emprendió por cuenta propia una complicada y trabajosa aventura financiera destinada a paliar la desastrosa situación económica del Reino de Murcia.

Efectivamente, el 24 de febrero de 1647, convoca Camerino en el convento de S. Felipe de Madrid a sus amigos y seguidores y constituye una Banca, la "Compañía de Jesús, María, Joseph del Desempeño que se ha permitido hazer y formar a pedimento de la ciudad y Reyno de Murcia ${ }^{3} »$, Compañía que tuvo una vida efímera pues un decreto del 30 de septiembre de 1647 suprimió todas las Bancas excepto las de cuatro banqueros genoveses.

Pero además de por su trabajo de burócrata y arbitrista, los años madrileños de Camerino se caracterizaron, sin duda, por su participación en la vida académica y literaria, hecho que seguramente le permitió establecer contacto con poetas y dramaturgos como Ruiz de Alarcón, Lope de Vega, Vélez de Guevara, Guillén de Castro o Vicente Espinel ${ }^{4}$. Sabemos que fue miembro de la Academia de Mendoza, pues aparece retratado en un «Vexamen» compuesto por uno de sus promotores, Anastasio Pantaleón de Ribera ${ }^{5}$. Participó asimismo en el homenaje póstumo a Montalbán y en una contienda poética organizada con motivo de la muerte de D. Sebastián Carlos ${ }^{6}$.

Contra lo que sostiene Ezio Levi y Evangelina Rodríguez no participó Camerino en la Academia Burlesca celebrada en el Retiro en 1637. Dichos auto-

2 Poco se sabe de la cronología del autor. E. Levı sostiene que era joven cuando publicó las Novelas Amorosas - H. SERIS puntualiza que su edad podrfa fluctuar entre los veinte y los veintiocho años- y que debió morir alrededor de 1660 , pues la última noticia que se tiene de él es de 1655 con la aparición de La Dama Beata. E. Rodriguez disiente en este punto alegando la presencia en el Archivo Comunale de Fano de un documento firmado por Giusseppe Camerino, fechado el 17 de junio de 1660, en el que evidencia que en ese año todavía ostentaba su cargo en la Nunciatura.

${ }^{3}$ Ms. 18.722 de la B.N.M. Sobre este tema es interesante el trabajo de JEAN VILAR «El caso de Camerino: literatura, política y arbitrismo*, Literatura y economía. La figura satírica del arbitrista en el Siglo de Oro (Madrid: Revista de Occidente, 1973), págs. 276-288.

4 Todos ellos le dedican poemas laudatorios en los preliminares de las Novelas Amorosas.

5 Quaderno de versos (Ms. 3.941 de la B.N.M., fols. 18-20) Tan malintencionado es el retrato, que Jose Pellicer de Tovar, en su edición de las obras de Pantaleón De Ribera, sustituye el nombre de «Joseph Camerino» que daba título al Vexamen, por el de «Don Carinemo»: Obras de Pantaleón de Ribera (Madrid: Francisco Martínez, 1634), págs. 100-101.

6 A la muerte del doctor luan Perez de Montalban. Endechas,» Lágrimas panegtricas a la ... muerte del gran poeta ... Juan Perez de Montalban, ed. Pedro Grande de Tena (Madrid: Imprenta del Reino, 1639),pág. 60. «Romance de Joseph Camerino," Obelisco histórico y honorario ... a la ... Memoria del ... Señor Don Baltasar Carlos .... ed. Iuan Francisco Andrés (Zaragoza: Hospital de Nuestra Señora de Gracia, 1646), págs. 29-29. 
res basan su aserto en la presencia de un soneto de Camerino en el manuscrito 3.773 de la Biblioteca Nacional de Madrid, sin saber que dicho manuscrito no corresponde a la Academia Burlesca sino al Certamen que se hico en presencia de su mag. en el Retiro el año de $1638^{7}$. Certamen en el que interviene nuestro autor junto con Quevedo, Calderón de la Barca, Pellicer de Tovar, Céspedes ...

Aclarada esta cuestión, diremos que los afanes literarios, y no sólo los literarios, de Camerino, cristalizaron en tres obras: las Novelas Amorosas, publicadas en 1624, Discurso político sobre estas palabras: A fe de hombre de bien en 1631, y La Dama Beata aparecida en 1655.

Las Novelas Amorosas de José Camerino constituyen una de las múltiples colecciones de novelas que se publicaron en España en el siglo XVII. Es sobradamente conocido que con la palabra novela se designaba entonces a lo que hoy llamamos novela corta, y que tanto el nombre como el género son de procedencia italiana. En realidad la palabra novela es de origen provenzal, pero es con la difusión del Decameron cuando se impone en toda Europa. Es también un hecho pacíficamente admitido que la novela corta española nace con Cervantes, pues las colecciones de relatos anteriores a las Novelas Ejemplares, o bien son traducciones de autores italianos o bien son intentos de componer, en lengua española a la manera italiana.

Pero volvamos a nuestro tema. Bajo el título Novelas Amorosas, publica José Camerino doce relatos independientes, sin una "cornice» que los enmarque a la manera boccacciana (quizás sea éste el único tópico ausente de la colección). La primera de ellas, «La voluntad dividida», nos cuenta, en un marco de novela morisca, la historia de un hombre enamorado de dos mujeres. «La firmeza bien lograda» es una novela entre pastoril y bizantina, situada en Asia Menor en la antigüedad clásica. «Los peligros de la ausencia» tiene como tema los amores de Camilo y Laudemia y la lucha interna de César que se debate entre la fidelidad a su amigo Camilo y su amor por Laudemia. Transcurre en la Italia del siglo VI. «El casamiento desdichado» cuya acción se sitúa entre el Madrid de los Austrias y París, presenta con gran crudeza un caso de venganza de sangre. «El pícaro amante» considerada tradicionalmente la

7 Existen dos manuscritos de la Academia Burlesca: uno de la Biblioteca de Osuna, recogido por Bartolomé Gallardo en Ensayo de una biblioteca española de libros raros y curiosos (Madrid: Rivadeneira, 1863-1889) vol. I, pág. 909, n. ${ }^{\circ} 853$-, y otro de la Biblioteca del Arsenal de París que edita Morel Fatıo: «Académie Burlesque célébrée par les Poetes de Madrid au Buen Retiro en 1637», en L'Espagne au XVle et au XVIle siécles (Heilbronn, 1878), págs. 603-676. He confrontado la edición de MOREL FATIO, la relación de GALLARDo y el manuscrito 3.773 de la B.N.M., y éste último no tiene nada que ver con los dos anteriores, y es normal que así sea ya que no corresponde a la Academia Burlesca sino al Certamen celebrado en el Retiro. 
mejor novela de la colección, nos cuenta la vida apicarada de dos estudiantes y cómo uno de ellos consigue hacer un casamiento ventajoso que le permite ascender económica y socialmente. La novela acaba con el triunfo del impostor, a través del cual condena, a mi parecer, Camerino, el arribismo burgués de la familia protagonista que, en su afán de ennoblecerse, actúa imprudentemente y es engañada por un pícaro, el cual, a pesar de que gracias a las riquezas de su mujer se hace pasar por un caballero, sigue comportándose de acuerdo con su condición, esto es, vilmente, pues aunque el dinero pueda romper muchas barreras solamente la sangre puede hacer virtuosas a las personas. Se da el hecho curioso de que esta novela fue utilizada por La Geneste en su versión del El Buscón aparecida en $1633^{8}$. La Geneste sustituye las últimas aventuras de Pablos por un largo capítulo final que desemboca en la boda del protagonista con una rica heredera sevillana. Tradicionalmente se pensaba que este cambio se debía a la invención del autor francés, pero Cecile Cavillac ha evidenciado que todo el material proviene de «El pícaro amante» de Camerino?.

«La ingratitud hasta la muerte» nos lleva de nuevo a la antigüedad clásica, a los bosques de Creta, donde transcurre una historia de ninfas, pastores, sátiros ... y un caballero convertido en pastor por amor. «El amante desleal» es una novelita de amor y aventuras que transcurre entre España y Flandes y que tiene un final sorprendente, pues acaba con el tema del hijo asesinado. Después de numerosos avatares y peripecias, D. Fadrique llega a Valencia, su ciudad natal, donde sus padres, a causa del tiempo transcurrido, no le reconocen. El no se identifica pues quiere cerciorarse primero de sus situación con la justicia (se había ido huyendo de ella por la muerte de un rival) y, haciéndose pasar por un amigo de sí mismo, se hospeda con su familia entregándoles todas sus joyas y dineros para que los guarden. La vista de tanta riqueza despierta la codicia del padre, que concierta con otro hijo suyo matar al huésped, hecho que efectúan mientras D. Fadrique duerme, arrojando el cadáver a un pozo. La llegada de la protagonista buscando reparar su honor perdido, hace que se descubra el crimen y que los culpables reciban un castigo ejemplar. Esta historia del hijo que, después de una larga ausencia, vuelve enriquecido y de incógnito a la casa de sus padres los cuales, no sólo no le reconocen sino que, movidos por la codicia, lo matan mientras duerme para quedarse con sus riquezas, circulaba por Europa, en distintas versiones, desde 1618. En ese año aparece en

8 L'aventurier Buscon, histoire facecieuse (Paris: Pierre Billaine, 1633).

9 Cfr. Ceclle Cavillac, «'El Pícaro Amante' de José Camerino et L'aventurier Buscon de La Genese: étude d'un cas de médiation litteraire», Revue de Littérature Comparée XLVII (1973). págs. 399-411. 
Londres y en París, en ambas versiones el autor es desconocido ${ }^{10}$. En 1621 aparece publicada en París por Jean Baudoin ${ }^{11}$, y en Amberes por el jesuita Antoine Barlinghem que la incluye en una obra suya titulada Zoopaideia. En Alemania aparece en la crónica de Gottfried (1624) y en la de Schultze (1650). Según el exhaustivo estudio de María Kosko sobre el tema ${ }^{12}$, éste forma parte de una tradición popular internacional, cuyos orígenes se ignoran, y desde el siglo XVII se encuentra en las crónicas de la Guerra de los Treinta Años, en los sermones, en las recopilaciones de anécdotas, etc... Desde las primeras obras del siglo XVII hasta nuestros días, el tema ha seguido inspirando cuentos, dramas, baladas, novelas ... como ejemplo más notable recordemos $\mathrm{Le} \mathrm{Ma-}$ lentendu de Camus. Lo que nos interesaría saber a nosotros es cómo llegó el tema a Camerino. ¿Tuvo acceso a la Zoopaideia de Barlinghem o quizá en la Nunciatura, donde trabajaba, oyó a alguien comentar el caso? ¿O lo leyó en alguna hoja volantes, si es que existió? Y en cualquiera de los casos, ¿Por qué no explotó las posibilidades del tema, que eran muchas, en lugar de dejarlo relegado al desenlace?

En «La triunfante porfía» aparece de nuevo el elemento morisco para animar una historia de amor entre una mujer soberbia que desprecia a todos los hombres, y el único hombre que osa burlarse de ella. "La soberbia castigada» nos lleva nada menos que al Cádiz fenicio para contarnos la desdichada historia de Artamia, otra mujer soberbia y altiva, que cuando se enamora cae en una espiral de degradación que le lleva a la locura. «Los efectos de la fuerza» narra la desastrosa historia de Estrella y Don Sebastián que, enamorados desde niños, se ven impelidos, a causa de la pertinaz oposición familiar a sus relaciones, a quebrantar las más sagradas leyes religiosas y sociales, por lo que son castigados con una muerte horrenda. Esta novela es interesante, sobre todo, por un insolito episodio de cautivos en el que Estrella se entrega a su amo el moro ante los ojos de su amante D. Sebastián ${ }^{13}$. Después reniega de su fe y se casa con el moro, para acabar huyendo con D. Sebastián. Ambos mueren en una playa desierta devorados por las fieras. Y por último «La catalana hermosa», especie de «pot-

${ }^{10}$ Newes from Perin in Cornwall of a most bloody and exempled Murther very lately commited by a Father on this owne Sonne... (1618). En París aparece con el título Histoire admiable y prodigieuse d'un Pére et d'une M'ere qui ont assassiné leur prope Fils sans le cognoistre. Arrivéé en la ville de Nimes en Langedoc, au mois d'Octobre dernier, 1618.

11 Acte abominable d'un Pére avare et desnaturé, lequel apres avoir tué son Fils s'e estrangle luy-mesme..., aparece incluido en una colección de relatos.

12 «Le Fils Assassiune», FF Communications LXXXIII, n. 198 (1966).

13 Vid. ALBERT MAS, «La turquerie macabre: Joseph Camerino et Antonio de Eslava», Les turcs dans la Littérature Espagnola (París, 1967) 1: págs. 549-554; GEORGE CAMAMIs, Estudios sobre el cautiverio en el Siglo de Oro (Madrid: Gredos, 1977) págs. 198-201. 
purrí en el que se entremezclan todos los elementos que han ido apareciendo anteriormente con algunos nuevos, y así encontramos duelos, rivalidades familiares, equívocos, aventuras marítimas, un loco-sabio, cautiverio, mujer disfrazada de hombre, anagnórosis...

A pesar de lo brevísimo del repaso, puede apreciarse la pluralidad espaciotemporal de las historias y sus múltiples conexiones con otros géneros novelescos. Este hecho se debe, a mi entender, a que siendo el amor el tema de las doce novelas ${ }^{14}$, los personajes arquetípicos y el planteamiento de todos los relatos prácticamente idéntico (encuentro y enamoramiento; proceso de seducción; aparición de dificultades y lucha para vencerlas; final feliz o desgraciado dependiendo del designio didáctico), el autor se ve en la necesidad de introducir elementos que rompan la monotonía, que atraigan la atención del lector ${ }^{15}$. Para ello, y quizá también para demostrar sus conocimientos - dedica su libro Camerino al «crítico lector ${ }^{16}$ », vuelve sus ojos a la tradición novelística anterior y trata de reflejarla entera - sin tener en cuenta las limitaciones que el género y sus propia capacidad noveladora imponían - alternando argumentos moriscos, bizantinos, picarescos, pastoriles... aunque en realidad lo que hace es injertar tópicos propios de estas novelas en el mismo tipo de relato codificado de amor y aventuras, de modo que tras una aparente diversidad, se esconde una uniformidad palmaria de caracteres, situaciones y conflictos. Otro tanto puede decirse del marco especial que, exceptuando un par de novelas, sufre continuas variaciones por mor de los viajes que por una u otra causa realizan los personajes, y que nos llevan desde Ormuz hasta Flandes pasando por el Cabo de Buena Esperanza, Asia Menor, Norte de África ... sin que ello comporte pluralidad de ambientes ni de costumbres. En cuanto al tiempo de las historias, puede retrotraerse hasta los fenicios sin que por ello cambie un ápice la realidad presentada. Volviendo al espacio, hay que señalar la abundante presencia de la naturaleza

14 En cuestiones amorosas Camerino no es un teórico ni un innovador. El tratamiento que hace del tema se inserta dentro de la tradición del amor cortés y el neoplatonismo de la que recoge los aspectos más superficiales, aún así en conflicto, muchas veces, con las rígidas normas morales y sociales que él defendía y con su propia misoginia.

15 La altemancia y mezcla de argumentos en pro de la variedad amena era algo propio del humanista y se plasma en las silvas y misceláneas que tanto proliferaron en la segunda mitad del siglo XVI. El Barroco radicaliza el planteamiento y hace de la variedad «el primero de los valores que el mundo encierra», juzgándola *como un valor de fecundidad y de placer», José ANTONı MA. RAVALL, La Cultura del Barroco (Barcelona: Ariel, 1980) pág. 377.

16 dirige su obra CAMERino al «crítico lectors apartándose de los apelativos usuales en los prólogos de la época — Cfr. Alberto Porqueras Mayo, El prólogo como género literario (Madrid: C.S.I.C., 1957) - y utilizando un adjetivo que deja traslucir, por un lado, el temor a que la obra sea tratada con dureza, y que por otro selecciona al lector capaz de «criticar», es decir, de juzgar su ejercicio literario. 
en las novelas y, lo que es más interesante, es que algunas ocasiones Camerino se sirve de ella para proyectar los estados anímicos de los personajes de un modo muy similar a como se hará en el Romanticismo.

Otra destacada característica de las Novelas Amorosas que no quiero pasar por alto, es su fuerte carga ideológica. A través de las páginas de sus novelas, Camerino se convierte en portavoz de los principios religiosos y morales tridentinos, de los ideales del Imperio y de los valores de la sociedad estamental, hasta el punto de que su narrativa está condicionada en gran medida por su afán moralizante y proselitista. Las «enseñanzas» que nos brinda pueden aparecer como algo externo a la acción, en forma de comentarios y apostillas en boca del narrador y los personajes, o pueden emanar del curso de la historia y del final desgraciado o feliz de los mismos ${ }^{17}$. Este hecho nos lleva a considerar el valor propagandístico de esta literatura que, como destinada al entretenimiento de un público numeroso, era un vehículo ideal para transmitir mensajes proclives al mantenimiento del «status quo ${ }^{18}$ ».

En cuestiones de estilo Camerino es un seguidor a ultranza de la moda gongorina y trata de llevar a su prosa las excelencias del modelo. Sus afanes cultistas cristalizan en una sintaxis plagada de participios y gerundios en construcciones absolutas, de períodos larguísimos, de hipérbatos, de sintagmas no progresivos.... cristalizan también en el uso abundantísimo de imágenes, metáforas, epítetos, alusiones mitológicas y cultismos. Tampoco es ajeno el autor a procedimientos conceptuales como la antítesis, paranomasia, zeugmas, dilogías, juegos de palabras... Tan profundo era su conocimiento del idioma que podía manipularlo a su gusto. En ese gusto suyo precisamente radica el problema.

Con todo, lo preocupante de José Camerino no es su excesivo didactismo, ni su vana pretensión de variar constantemente de asunto, ni lo abigarrado de su prosa, ni que los temas, motivos, procedimientos narrativos, recursos estilísticos.. de sus novelas sean en su mayor parte convencionales y tópicos ${ }^{19}$. Lo ver-

17 En ningún momento se interesa el autor por los problemas de los personajes, ni les da oportunidad de rectificar, ni considera los motivos exculpatorios, sino que, planteando el conflicto, quebrantada la ley, los condena sin remisión, lo que revela, a mi parecer, un temperamento dogmático e intransigente cuando menos.

18 Sobre este tema vid., entre otros, José AnTonio MAravall, La cultura del Barroco, citada, y Teatro y literatura en la sociedad barroca (Madrid: Seminarios y Ediciones, 1972); J. M. DíEz Borque, Sociología de la comedia española del siglo XVII (Madrid: Cátedra, 1976), y JuAN Goytisolo «El mundo erótico de María de Zayas», Disidencias (Barcelona: Seix Barral, 1977) página 396.

19 Las Novelas Amorosas pueden encuadrarse en lo que Sklovski llama «argumento-crucigramam, en el que unos elementos dados se combinan según pautas establecidas. Vid. VICTOR SKLovski, Sobre prosa literaria (Barcelona: Planeta, 1971), 396. 
daderamente grave de nuestro autor es, a mi parecer, y sin restar importancia a todo lo anterior, la infinita inocencia con que utiliza ese material convencional y en algunos casos antiquísimo, aceptándolo sin un titubeo, sin un asomo de ironia, y presentándolo al lector como si fuese algo necesario, natural y verdadero.

Es precisamente esa falta de conciencia artística, esa escasa capacidad para maniobrar con los materiales estéticos que la tradición y su época le brindaban, lo que hace de José Camerino un espejo en el que podemos ver con extraordinaria claridad, la otra cara de la literatura del siglo XVII, un perfecto ejemplo de cómo funcionaban y en qué podían convertirse aquellos elementos que en manos de Cervantes, Lope o Góngora se mostraban tan llenos de vida y de belleza. Del mismo modo, novelas como las aquí comentadas, constituyen un claro exponente de la situación de la narrativa española del seiscientos que, olvidándose de las grandes aportaciones de La Celestina, el Lazarillo, Cervantes... va metiéndose paulatinamente en un callejón sin salida.

Para terminar, decir que, a pesar de todo lo anteriormente expuesto, las Novelas Amorosas no son peores que tantas otras colecciones de la época, aunque algunas de ellas hayan tenido mayor fortuna en el campo editorial. En su conjunto constituyen una parte importante y significativa de la literatura barroca que es necesario rescatar del olvido si queremos que nuestra historia literaria sea completa y objetiva. 